\title{
Effect of Circumferential and Axial Grooves on the Retention of Provisionally Cement-Retained Implant-Supported Crowns (In Vitro Study)
}

\author{
Badawi $\mathrm{H}^{1} B D S$, Aboushady $\mathrm{Y}^{2} P h D$, Azer $\mathrm{A}^{3} P h D$.
}

\begin{abstract}
:
Introduction: Retention of provisionallycemented implant-supported restorations plays an important role in success of the treatment. Uncemented restorations may cause several problems such as restoration swallowing, increased bone loss and prosthesis failure. Therefore, suitable cement compromising between retention and retrievability as well as extra-means of abutment retention might be preferable for durable implant restorations.

Objectives: This study introduced circumferential and axial grooves on implant abutments as retentive promoters and evaluated their effect on the retention of crown copings cemented to implant abutments with provisional luting cements.

Materials and methods: Twenty straight titanium implant abutments were divided into 4 groups (n=5): without grooves, with 1 axial groove, with 2 circumferential grooves, and with 3 circumferential grooves. Twenty nickel chromium crown copings were fabricated to fit all 20 abutments. The copings were cemented to each group of abutments with non-eugenol provisional cement. After storage for 24 hours in $100 \%$ humidity at $37^{\circ} \mathrm{C}$, specimens were subjected to 500 cycles of thermal cycling, then 5000 cycles of compressive load to simulate the thermal and mechanical stresses in the oral environment. Tensile strengths were conducted with a universal testing machine and tensile stresses were recorded in Newton. After the retention test, the copings and abutments were evaluated for cement failure mode with Stereoscopic Microscope. Collected data were analyzed using one-way analysis of variance (ANOVA) and Tukey's HSD tests $(\alpha=.05)$.

Results: The mean tensile strength of the three circumferential grooves was significantly higher than the other groups ( $\mathrm{P}<0.001)$ while there was no significant difference between the axial groove and control group $(\mathrm{P}=0.999)$. The cement failure mode was generally adhesive in nature, although some mixed failures were observed.

Conclusion The surface modification of an implant abutment by means of circumferential grooves was found to be an effective method of improving the retention of crown copings cemented with non-eugenol cement.
\end{abstract}

Key Words: Abutment, Implant, retention, grooves, retrievability

${ }^{1}$ Conservative Dentistry Department, Faculty of Dentistry, Alexandria University.

${ }^{2}$ Professor of Fixed Prosthodontics, Conservative Dentistry Department, Faculty of Dentistry, Alexandria University.

${ }^{3}$ Lecturer of Fixed Prosthodontics, Conservative Dentistry Department, Faculty of Dentistry, Alexandria University.

\section{INTRODUCTION}

Successful osseointegration of implant materials and soft tissue management techniques have allowed the single tooth implant procedure to become a viable treatment option (1).

Implant-supported fixed prostheses may be cemented or screw-retained onto the implant abutments. The most common advantages of the cement-retained crown are enhanced posterior esthetics, ability to correct minor casting misfits between superstructure and abutments, and reduced technique sensitivity both in the clinic and the laboratory. Their greatest disadvantage is the lack of a reliable means of retaining and then retrieving the superstructure for routine care and maintenance $(2,3)$.

Crown retention is a very important factor in the success of fixed restorations. The necessity for retention and resistance of cement-retained restorations are related to the geometry of the abutment preparation, surface area, abutment height, surface roughness, and cement type.Surface roughness and luting agents are factors that can be controlled by the clinician (4).The choice of cement is one of the most important factors controlling the amount of retention attained. A selection of cement that is too retentive could lead to damage due to use of aggressive removal techniques; while selection of cement that is not retentive enough could be a potential source of patient's discomfort (5).

Provisional cementation is preferred at the delivery of final restoration. The implant differs from a natural tooth in that it does not provide early symptoms of occlusaldisharmony. The soft tissue health and hygiene may be evaluated at the follow-up appointment and may mandate the modification of embrasures or pontics to improve access. The disadvantage of provisional cements on natural teeth is the risk of cement failure resulting into decay. As implants do not decay, temporary cement often may be used as definitive cement and permit an easy retrieval of the prosthesis if intermediate or long term complications develop as recommended by many authors (6-11). This use of temporary cements has been promoted as excess extruded cement may dissolve within a short period of time, however, not all temporary cements may dissolve rapidly particularly when located subgingivally (12). 
Several studies evaluated the effectof abutment surface roughness by sandblasting on bond strength because of the resulting microretentive ridges (13-16).A recent study compared the effects of nano and microabrasive particles in roughening abutment surface for increasing retention (17). Abutment surface modification with diamond bur could also improve the retention of cemented restorations (18). Other studies suggested that varying abutment height and platform size may affect bond strength (19-23). Also, modification of abutment axial walls may have positive effect on retention of cemented castings (24). A further study was done to evaluate the effect of extending the casting into screw access channel to increase its retention when provisionally cemented (25).

The purpose of this study was to introduce the use of circumferential and axial grooves on implant abutments and to evaluate their effect on the retention of provisionally cemented implant restorations.

The null hypothesis was that circumferential and axial grooves would not affect the retention of cemented copings.

\section{MATERIALS AND METHODS}

Twenty straight abutments (Biohorizons, Birmingham, USA) $(4,5 \mathrm{~mm}$ diameter and $8.0 \mathrm{~mm}$ height $)$ with abutment screws, corresponding stainless steel laboratory internal implant analogs $(4.5 \mathrm{~mm}$ diameter) (Biohorizons, Birmingham, USA) and waxing sleeves (Biohorizons, Birmingham, USA) were used (Fig.1).

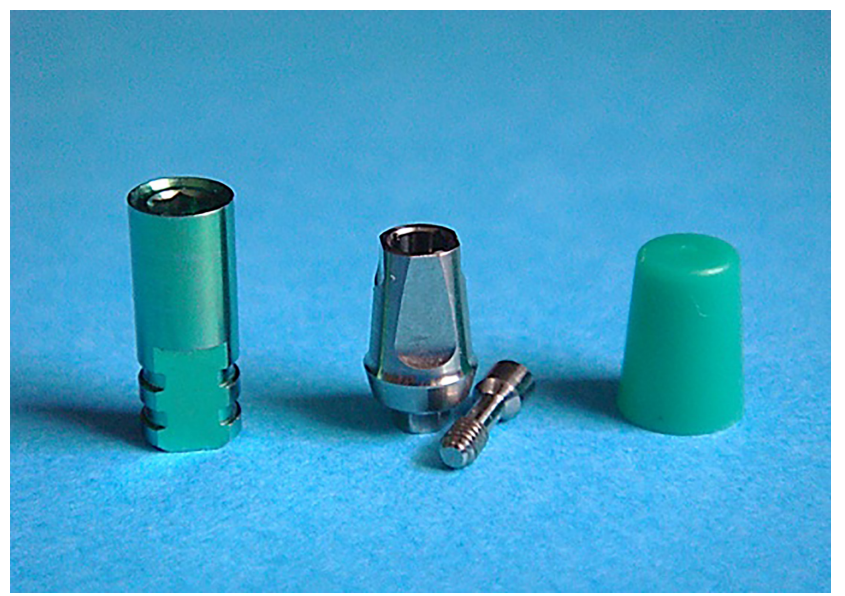

Fig. 1: Prosthetic components

Abutments were divided into 4 groups of 5 abutments each: Group I (control group): without grooves, Group II: with 1 axial groove $(0.5 \mathrm{~mm}$ width, $0.4 \mathrm{~mm}$ depth and 4 mm length) (3), Group III: with 2 circumferential grooves ( $0.5 \mathrm{~mm}$ width, $0.4 \mathrm{~mm}$ depth, $2 \mathrm{~mm}$ in between them) and Group IV: with 3 circumferential grooves $(0.5 \mathrm{~mm}$ width and $0.4 \mathrm{~mm}$ depth, $1.5 \mathrm{~mm}$ in between them) (27). Other than the type and number of grooves, the abutments were identical. Grooves were done by BB25-1 small lathe (SJMC Machine Tools Co., Ltd-China).

Each specimen was embedded and stabilized in a prefabricated split copper mold filled with selfpolymerizing acrylic resin (Orthoplast; Vertex-Dental,
Zeist, The Netherlands) to form acrylic bases to facilitate the testing procedure (Fig. 2).

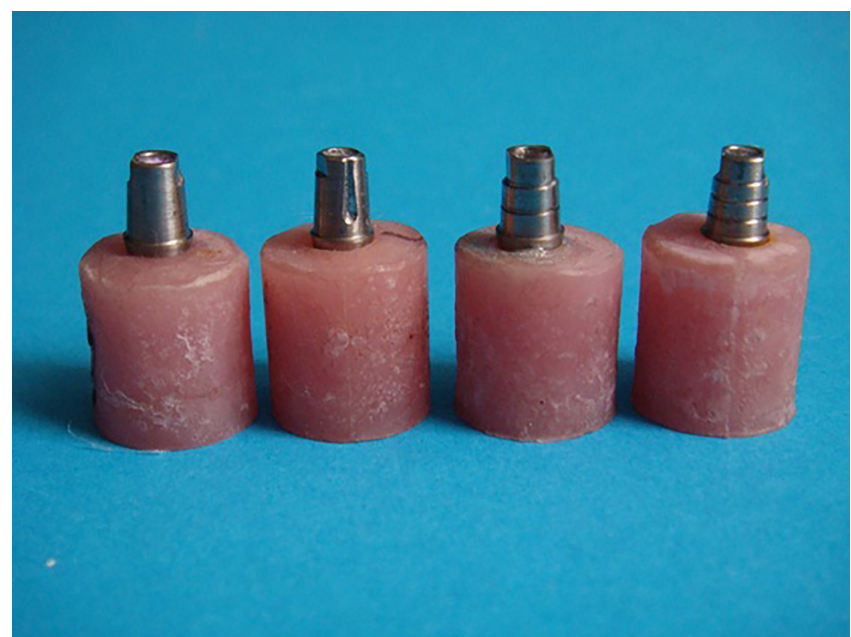

Fig. 2: Specimens representing the four groups in acrylic bases.

Then, the abutment screws were tightened with hex driver and calibrated torque wrench (Biohorizons, Birmingham, USA) to a torque of $30 \mathrm{~N} . \mathrm{cm}$ (according to manufacture instructions). Nickel Chromium crown copings (Ivoclar Vivadent, Amherst, USA) were fabricated from waxing sleeves (Biohorizons, Birmingham, USA), attached to it a wax loop (Technowax-wire; Protechno, Girona, Spain) on top of it an occlusal platform wax (Cavex, Haarlem, Netherlands) to provide a flat surface to receive the cyclic loads $(24,26)$. Two cotton pellets were compacted on top of the abutment screw of each abutment and screw access channels were sealed flush with softened and compacted modeling wax (Cavex, Haarlem, Netherlands) (26). The intaglio surfaces of the crown copings were sandblasted in the lab with $110 \mu \mathrm{m}$ aluminum oxide particles (Renfert, Hilzingen, Germany) at 2barometer pressure then rinsed thoroughly with water spray and dried with oil-free air (26). A RelyX Temp NE (3M ESPE. St Paul. USA) was mixed according to the manufacturer's instructions and applied into coping intaglio with small brush to completely cover all the internal walls (3).

Each crown coping was seated on the corresponding abutment and held in place with finger for 10 seconds and then a static load of 6-kg weight was applied for 10 minutes to provide complete seating of the crown (18). Excessive cement was removed after setting with a plastic curette to avoid scratches on metal surfaces (27). After cementation, specimens were placed in an incubator at $100 \%$ humidity at $37^{\circ} \mathrm{C}$ for 24 hours, then subjected to 500 cycles in a thermocycling machine between $5^{\circ} \mathrm{C}\left( \pm 2^{\circ} \mathrm{C}\right)$ and $55^{\circ} \mathrm{C}$ $\left( \pm 2^{\circ} \mathrm{C}\right)$ with a 20 seconds dwell time in each bath, and 5-10 seconds interlude between water baths as in-vitro simulation of thermal stresses in oral environment (26). Then specimens were subjected to 5000 cycles of compressive load to simulate 6 months of average human masticatory function (26). The specimens were mounted on a universal testing machine (Comten Industries Inc, USA) and a vertical tensile stress was applied at a crosshead 
speed of $2.5 \mathrm{~mm}$ per minute, to dislodge the copings from the abutments (Fig. 3).

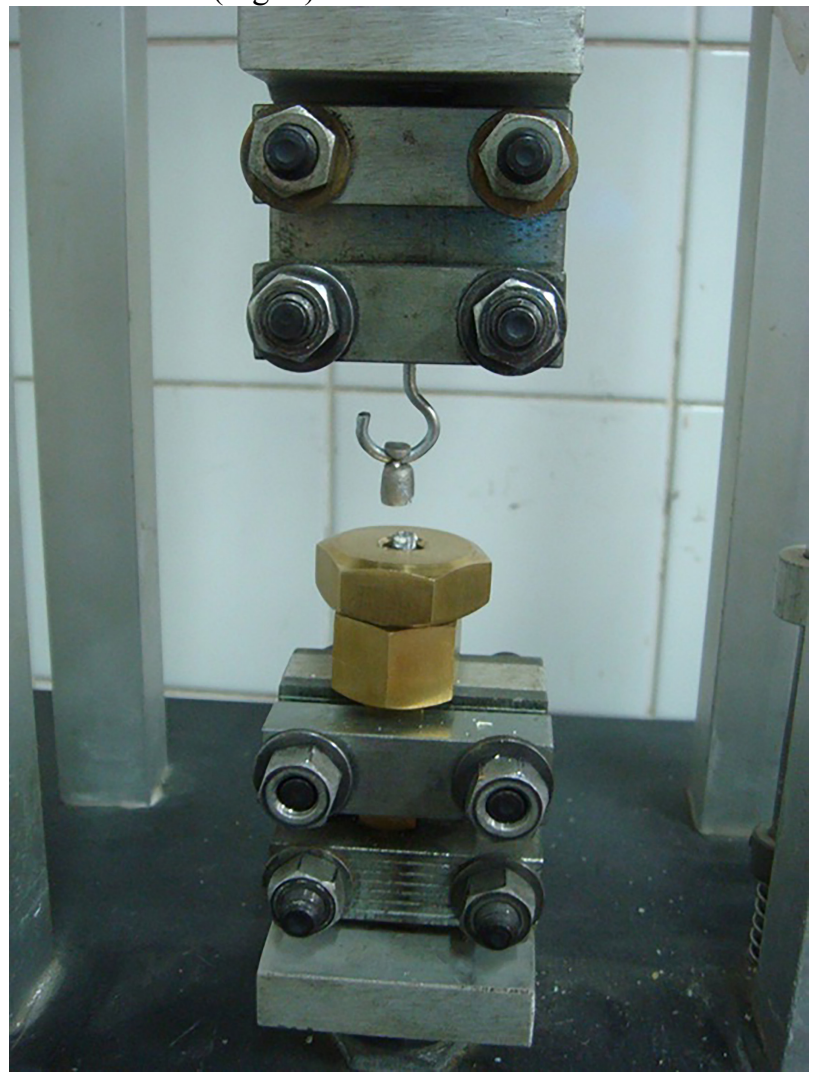

Figure 3: coping dislodged from the abutment - universal testing machine

The peak load to dislodgment was recorded in Newton $(\mathrm{N})$ and used to indicate the retentive value.

After the retention test, the copings and abutments were evaluated for failure mode (Fig.4) according to the location of the residual cement with $\mathrm{x} 5$ magnification Stereoscopic Microscope (Olympus, Tokyo, Japan). Full thickness residues on the abutment or coping were denoted as adhesive failure. Cohesive failure was denoted when the failure was within the cement and partial thickness residues were seen on the abutment and the opposing surface of the coping. A combination of adhesive and cohesive failure was considered a mixed failure(27). Collected data were analyzed by IBM SPSS software, using one-way analysis of variance (ANOVA) and Tukey's HSD tests.

\section{Statistical analysis}

Data were fed to the computer and analyzed using IBM SPSS software package version 20.0.

Qualitative data were described using number and percent. Quantitative data were described using minimum and maximum, mean and standard deviation and median.

For normally distributed data, comparison between the three studied groups were analyzed using F-test (ANOVA) and Post Hoc test (Tukey) for pair-wise comparisons, while for abnormally distributed data Kruskal Wallis test was used to compare between different groups and MannWhitney Test was assessed for pair-wise comparisons.
Significance of the obtained results was judged at the $5 \%$ level.

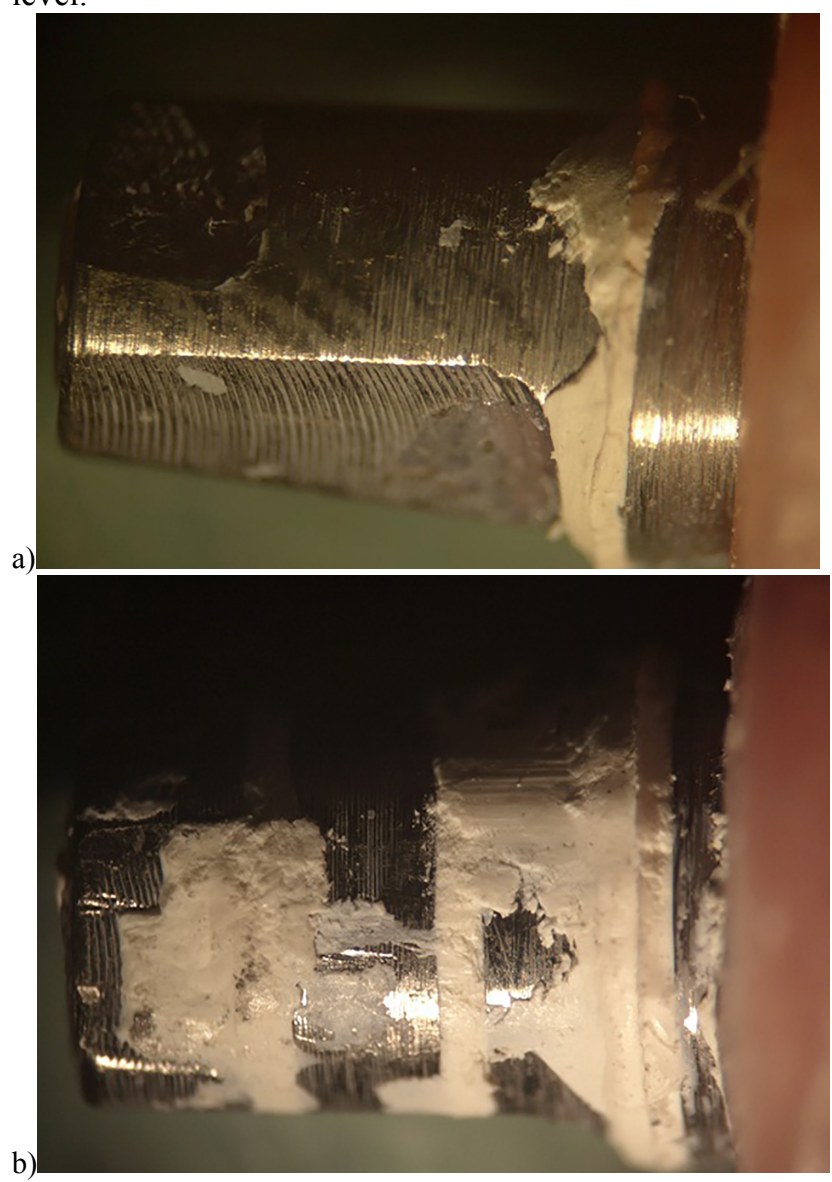

Fig. 4: Cement failure mode. a) adhesive type failure for Group I and II. b) mixed type failure for Group III and IV.

\section{RESULTS}

The one-way ANOVA indicated that the additional circumferential grooves significantly increased the retention of the copings. The retentive values of crown copings cemented on abutments of Group IV had the highest mean tensile bond strength $(157.52 \mathrm{~N})$, followed by Group III $(136.94 \mathrm{~N})$, then Group II (112.16 N), then Group I (control group) $(111.86 \mathrm{~N})$ as seen in (Fig.5) and (Table 1, 2).

Table 1: Mean tensile strength for various groups.

\begin{tabular}{||c|c|c|c|c|c|c||}
\hline & $\begin{array}{c}\text { Group I } \\
(\mathbf{n}=\mathbf{5})\end{array}$ & $\begin{array}{c}\text { Group II } \\
(\mathbf{n}=\mathbf{5})\end{array}$ & $\begin{array}{c}\text { Group III } \\
(\mathbf{n}=\mathbf{5})\end{array}$ & $\begin{array}{c}\text { Group IV } \\
(\mathbf{n}=\mathbf{5})\end{array}$ & $\mathbf{F}$ & p \\
\hline Specimen & & & & & & \\
Min.- & $108.30-$ & $108.50-$ & $133.20-$ & $153.80-$ & & \\
Max. & 116.80 & 116.80 & 141.60 & 161.70 & & \\
Mean \pm & $111.86 \pm$ & $112.16 \pm$ & $136.94 \pm$ & $157.52 \pm$ & $241.675^{*}$ & $<0.001^{\mathbf{*}}$ \\
SD. & 3.27 & 3.11 & 3.17 & 3.09 & & \\
Median & 111.60 & 111.90 & 136.80 & 157.60 & & \\
\hline
\end{tabular}

Table 2: One-way ANOVA for tensile strength. 


\begin{tabular}{||c|c|c|c|c|c||}
\hline Source & df & $\begin{array}{c}\text { Sum of } \\
\text { Squares }\end{array}$ & $\begin{array}{c}\text { Mean } \\
\text { Square }\end{array}$ & F & p \\
\hline Between Groups & 3 & 7261.31 & 2420.44 & $241.675^{\mathbf{*}}$ & $<0.001^{\mathbf{*}}$ \\
\hline Within Groups & 16 & 160.24 & 10.02 & & \\
\hline Total & 19 & 7421.55 & & & \\
\hline
\end{tabular}

Tukey's HSD test revealed that the mean tensile strength of Group IV was significantly higher than the other groups $(\mathrm{P}<0.0001)$ while there was no significant difference between Group II and Group I (control group) ( $\mathrm{P}=0.999)$ (Table 3).

Table 3: Tukey's HSD test.

\begin{tabular}{||c|c|c|cc||}
\hline Group & No & Mean \pm SD & \multicolumn{2}{|c|}{ Tukey HSD test } \\
\cline { 1 - 3 } I & 5 & $111.86 \pm 3.27$ & \multirow{2}{*}{ I:II $=0.999$} & I:III $<0.001^{*}$ \\
II & 5 & $112.16 \pm 3.11$ & I:IV $<0.001^{*}$ & II: III $<0.001^{*}$ \\
\cline { 1 - 2 } III & 5 & $136.94 \pm 3.17$ & II:IV $<0.001^{*}$ & III:IV $<0.001^{*}$ \\
\cline { 1 - 2 } IV & 5 & $157.52 \pm 3.09$ & \\
\hline
\end{tabular}

The cement failure mode seen in this investigation was generally adhesive in nature, although some mixed failures were observed. Copings cemented on abutments in Group I and Group II exhibited adhesive type failure occurring at abutment/cement interface, where full thickness of cement remnants were found primarily (more than $50 \%$ ) over the inner-surface of the copings while small full thickness cement remnants were found on the abutment shoulder. Group III and Group IV exhibited mixed (adhesive/cohesive) type failures with greater than $50 \%$ of full thickness cement remnants being found on the coping intaglio denoting adhesive failure mode. While, partial thickness cement remnants were found on abutment surface within and around its circumferential grooves as result of cohesive failure mode.

\section{DISCUSSION}

In this study, the effect of additional grooves of the abutments on the retention of the coping was evaluated. This study demonstrated that adding circumferential grooves to abutments increased the abutments surface area by production of cement lock against dislodgement forces, thus increased the retention of provisionally cemented crowns in comparison to axial groove and control group.

There are so many factors involved in retention of implant-supported crowns. The factors like abutment configuration and height of the abutment are determined by the particular clinical situation and cannot be changed as per the clinician's choice. Abutment surface modifications a factor that can be easily altered to influence the amount of retention required.

When selecting a luting agent, it is important for the cement to be easily manipulated and removed without any damage to implant components. Since there is no risk of decay on the abutments, implant restoration is cemented with temporary cements at delivery appointment as they are much weaker than definitive cements and permit retrievability of the restorations. In this study, RelyX NE cement was used as non-eugenol temporary cement for implant restoration as suggested by many authors when retrievability is needed (6-11). While Mehl et al (3) suggested zinc phosphate and glass ionomer cements for semipermanent cementation.

However, many problems encountered with provisional cements such as their insufficient resistance to functional force. Therefore where temporary cements cannot maintain proper retention for restoration, additional means of retention must be done. Numerous studies have been carried out to test the effect of abutment surface modification on the retention of implant restoration. In this study, surface modification of implant abutment by means of circumferential grooves was found to be an effective method of improving the retention of cast crowns cemented with non-eugenol temporary cement. This was similar to the findings of de Campos et al (15), Lewinstein et al (27) and Sahu et al (28).

The tensile strength values in this study suggested that addition of circumferential grooves increased the retention of RelyX Temp NE. The mean retentive forces werefor Group I (111.86 N), Group II (112.16 N), Group III $(136.94 \mathrm{~N})$ and Group IV $(157.52 \mathrm{~N})$. Since the experimental conditions of other studies were not exactly the same, the basis of comparison for results is questionable. Wolfart et al (29) investigated the retention of copings cemented with various cements to abutment with axial groove without thermocycling or cyclic loading; their reported retentive force was $177 \mathrm{~N}$ for Freegenol. Lewinstein et al (27) evaluated the effect of circumferential grooves on the retention of cast copings cemented with various types of cement on implant abutments after thermocycling but without cyclic loading. Theyreportedthat the mean retentive forces for no grooves were $170 \mathrm{~N}$ for Tempbond NE, for 2 circumferential grooves were $203.8 \mathrm{~N}$ and for 3 circumferential grooves were $241.9 \mathrm{~N}$. Their higher values obtained for samples with retentive grooves were similar to those reported by Sahu et al (28). In this study, the low retention values could be attributed to the lifting effect of thermocycling to the copings from their abutments and the compressive cycling loading, which when combined together, had detrimental effect on retentive properties of various cements.

Mansour et al (30), Alfaro et al (31) and Dudley et al (26) in their studies reported that all tested cements demonstrated adhesive failure to crown coping surface due to the rough sandblasted coping intaglio which provided greater micromechanical retention than the smooth titanium abutment surface. In this study, the bond failures of samples of abutments without groove and with axial groove occurred at the interface of cement and abutment. Remnants were found mostly on the coping intaglio denoting adhesive failure mode and some remnants found on the abutment shoulder, which could be attributed to the compaction of cyclic loading. According to the study of Lewinstein et al (27), cement failure mode was generally adhesive in nature, although some mixed failures were observed. Moreover, in this study, cement failure mode for circumferentially 
grooved abutments was similar (mixed failure). The pattern of cement remnants on the abutment indicated that circumferential grooves created a cement lock which affected the failure mode and location of remnants.

Under the variables investigated in this study, additional studies are recommended to quantify the effect of axial and circumferential grooves on the retention of copings cemented to short abutments by different temporary cements under long-term stimulation for better cement selection.

\section{CONCLUSIONS}

Within the limitations of this study, the following conclusions were drawn:

1. Abutment surface modification by axial groove had no significant effect on the retention of crown copings cemented to implant abutments by RelyX Temp NE cement.

2. The surface modification of an implant abutment by means of circumferential grooves could be an effective method of improving the retention of crown copings cemented with RelyX Temp NE cement.

\section{CONFLICT OF INTEREST}

The authors declare that they have no conflicts of interest.

\section{REFERENCES}

1. MischCE.Contemporary Implant Dentistry. St Louis, MO, Elsevier Mosby, 2008: 1-23

2. Michalakis KX, Hirayama H, Pavlos D, Garefis PD. Cement-retained versus screw-retained implant restorations: a critical review. Int J Oral Maxillofac Implants 2003; 18:719-28.

3. Mehl C, Harder S, Wolfart M, Kern M, Wolfart S. Retrievability of implant-retained crowns following cementation. Clin Oral Implants Res 2008; 19:1304-11.

4. Misch CE. Dental Implant Prosthetics. St. Louis: Elsevier-Mosby,2015:662-71.

5. Misch CE. . Dental Implant Prosthetics. St. Louis: Elsevier-Mosby, 2005:414-51.

6. Breeding, LC, Dixon, DL, Bogacki MT and Tietge, JD. Use of luting agents with an implant system: part I. J Prosthet Dent 1992; 68: 737-41.

7. Heinemann, F., Mundt, T. \&Biffar, R. Retrospective evaluation of temporary cemented tooth and implant supported fixed partial dentures. J CraniomaxillofacSurg 2006; 34: 86-90.

8. Kunt GE, Ceylan G, Yilmaz N, KÜçÜk BE. Luting agent effectiveness on implant crown retention. Int $\mathrm{J}$ Oral Impl CR 2011; 2:7-11.

9. Nejatidanesh F, Savabi O, Ebrahimi M, and Savabi G. Retentiveness of implant-supported metal copings using different luting agents. Dent Res J (Isfahan) 2012; 9: 13-8.

10. Jugdev J, Borzabadi-Farahani A, Lynch E. The effect of air abrasion of metal implant abutments on the tensile bond strength of three luting agents used to cement implant superstructures: an in vitro study. Int $\mathrm{J}$
Oral Maxillofac Implants. 2014; 29:784-90.

11. Reddy SV, Reddy MSN, Reddy CR, Pithani P, Kumar Sr, Kulkarni G. The infuence of implant abutment surface roughness and the type of cement on retention of implant supported crowns. J ClinDiagn Res 2015; 9:ZC05-7.

12. Armellini D, Bilko S, Carmichael RP, von Fraunhofer JA. Screw-retained prosthesis for Straumannimplant sites with limited interocclusal clearance. J Prosthodont. 2006; 15:198-201.

13. Michalakis K, Pissiotis AL, Kang K, Hirayama H, Garefis PD, Petridis H. The effect of thermal cycling and air abrasion on cement failure loads of 4 provisional luting agents used for the cementation of implant-supported fixed partial dentures. Int J Oral Maxillofac Implants 2007 ;22:569-74.

14. Kunt GE, Ceylan G, Yilmaz N. Effect of surface treatments on implant crown retention. J Dent Sci 2010;5:131-5.

15. de Campos TN, Adachi LK, Miashiro K, et al. Effect of surface topography of implant abutments on retention of cemented single-tooth crowns. Int $\mathrm{J}$ Periodont Res Dent 2010; 30: 409-13.

16. Kurt M, Külünk T, Ural C, Külünk Ş, Danişman Ş, Savaş S. The effect of different surface treatments on cement-retained implant-supported restorations. J Oral Implantol2013;39:44-51.

17. Rismanchian M, Davoudi A, Shadmehr E. Effect of Using Nano and Micro Airborne Abrasive Particles on Bond Strength of Implant Abutment to Prosthesis. Braz. Dent. J. 2015; 26:50-5.

18. Ganbarzadeh J, Nakhaei MR, Shiezadeh F, Abrisham SM. The Effect of Abutment Surface Roughness on the Retention of Implant-Supported Crowns Cemented with Provisional Luting Cement. J Dent Mater Tech 2012; 1: 6-10.

19. Emms M, Tredwin CJ, Setchell DJ, Moles DR. The effects of abutment wall height, platform size, and screw access channel filling method on resistance to dislodgement of cement-retained, implant-supported restorations. J Prosthodont 2007;16:3-9

20. Lee Dh, Suh Kw, Ryu JJ. Comparison of retentive forces of temporary cements and abutment height used with implant-supported prostheses. J korAcadProsthodont 2008; 43: 280-289.

21. Al Hamad KQ, Al Rashdan BA, Abu-Sitta EH. The effects of height and surface roughness of abutments and the type of cement on bond strength of cementretained implant restorations. Clin Oral Implants Res 2011; 22: 638-44.

22. Cano-Batalla J, Soliva-Garriga J, Campillo-Funollet M, Munoz-Viveros CA, Giner-Tarrida L. Influence of abutment height and surface roughness on in vitro retention of three luting agents. Int J Oral Maxillofac Implants 2012;27:36-41.

23. Saber F, Abolfazli N, Nuroloyuni S, Khodabakhsh S, Bahrami M, Nahidi R, Zeighami S. Effect of abutment height on retention of single cement-retained, wide- 
and narrow-platform implant-supported restorations. J Dent Res Dent Clin Dent Prospects 2012; 6:98-102.

24. Tan KM, Masri R, Driscoll CF, Limkangwalmongkol P, Romberg E. Effect of axial wall modification on the retention of cement-retained, implantsupported crowns. J Prosthet Dent 2012;107:80-5.

25. Naik S, Tredwin CJ, Nesbit M, Setchell DJ, Moles DR. The effect of engaging the screw access channel of an implant abutment with a cement-retained restoration. J Prosthodont 2009;18:245-8.

26. Dudley JE, Richards LC, Abbott JR. Retention of cast crown copings cemented to implant abutments. Aust Dent J 2008; 53: 332-9.

27. Lewinstein I, Block L, Lehr Z, Ormianer $Z$ and Matalon S. An in vitro assessment of circumferential grooves on the retention of cementretained implantsupported crowns. J Prosthet Dent 2011;106:367-72.

28. Sahu N, Lakshmi N, Azhagarasan N.S, Agnihotri Y, Rajan M, Hariharan R. Comparison of The Effect of Implant Abutment Surface Modifications on Retention of Implant-Supported Restoration with A Polymer Based Cement.JClinDiagn Res 2014:8; 239-42 .

29. Wolfart, M., Wolfart, S. and Kern M. Retention forces and seating discrepancies of implant retained castings after cementation. Int J Oral Maxillofac Implants 2006; 21:519-25.

30. Mansour A, Ercoli C, Graser G, Tallents R, Moss M. Comparative evaluation of casting retention using the ITI solid abutment with six cements. Clin Oral Implants Res 2002; 13:343-8.

31. Alfaro MA, Papazoglou E, McGlumphy EA, Holloway JA. Short-term retention properties of cements for retrievable implant-supported prostheses. Eur J ProsthodontRestor Dent 2004; 12:33-7. 